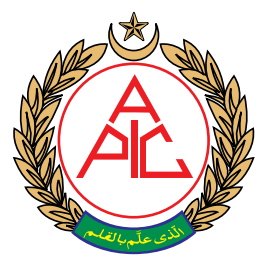

Department of Anesthesiology, Guilherme Álvaro Hospital, Santos, (Brazil)

Correspondence: Carlos R Degrandi Oliveira, Av. Dr Epitácio Pessoa, 131/104 Santos, SP (Brazil) 11045-301; E-mail: degrandi@gmail.com Received: 14 December 2019; Reviewed \& Accepted: 18 December 2019

\title{
Ethics in the operating room; the anesthesiologist's responsibility
}

\author{
Carlos R. Degrandi Oliveira, MD, TSA/SBA, MSc, Lawyer OAB-SP
}

\begin{abstract}
Anesthesiologists are professionals who practice their expertise in an acute process with a very short withdrawal period, which does not allow them many philosophical ramblings. However, they are professionals who must be increasingly concerned with ethical issues if they are to survive in the market and succeed in the face of everincreasing public expectations that all physicians must take care of in a shrinking world of today due to rapidly expanding social and electronic media. The operating room is particularly a place prone to interpersonal conflicts, as a wide range of healthcare professionals perform their tasks here, with overlapping and sometimes poorly defined areas of responsibility. Acting on behalf of their patients, anesthesiologists can be considered their moral agents and guardians in their shared work environment.
\end{abstract}

Key words: Ethics; Anesthesiology; Professionalism; Medical Responsibility.

Citation: Oliveira CRD. Ethics in the operating room; the anesthesiologist's responsibility Anaesth. pain \& intensive care 2019;23(4):333-336.

DOI: https://doi.org/10.35975/apic.v23i4.1163

“...I will apply dietetic measures for the benefit of the sick according to my ability and judgment; I will keep them from harm and injustice....”.

\section{Hippocrates of Kos (460-370 BC)}

Ethics is a set of knowledge extracted from the investigation of human behavior in trying to explain moral rules in a rational, grounded, scientific and theoretical way. Unlike the laws imposed on us, ethics is one of the mechanisms for regulating the social relations of individuals that aims to ensure social cohesion and harmonize individual and collective interests. ${ }^{1}$ It covers a wide area and can be applied to the professional side as well. Codes of professional ethics indicate how an individual should behave within his profession. All the duties and rights of the physician, whether morally or legally, are brought together under the aegis of medical ethics.

In traditional medical care, the physician assumes responsibility for the patient's welfare through an unwritten contract, the so-called Aquilian responsibility, ensured by consultation, by shaking hands, eye contact that denotes mutual understanding between the patient and the physician.

As stated by Beauchamp and Childress, there are four principles used to analyze bioethical clinical situations, e.g., beneficence, nonmaleficence, autonomy and justice. ${ }^{2}$

The principle of beneficence implies the obligation to maximize the benefit to the patient by reducing the risk of eventual injury. The professional must keep in mind that any intervention must bring benefits to the patient. In the field of medicine, beneficence is operationalized to act in the patient's interest, promoting health and preventing complications. This principle is not absolute, and its limits lie in the autonomous right of individuals to decide what they understand for their good, and what suits them.

The principle of beneficence always requires action, either to promote the good, or to prevent and eliminate damage, and from it follows a routine procedure for professionals, the assessment of the risk and benefit of each of their acts. Anesthesiologists should evaluate each patient's individual situation and not apply the same general decision to everyone. To do this, doctors must maintain their skills and update their medical knowledge regularly.

Futility in health is a significant area of debate and opposes the principle of beneficence. Generally, a futile treatment is one that is unable to produce a beneficial outcome. ${ }^{3}$

The principle of nonmaleficence, on the contrary, requires an abstention, avoiding harmful acts to 
the patient. It is universally consecrated by the Hippocratic aphorism primum non nocere, the "first, do no harm" doctrine, the purpose of which is not to inflict any harm, physical or moral, on the patient. It is the duty of the professional, in addition to helping, also not to cause any harm to the patient. The fact that a technique is possible does not mean that it will bring real benefit to the patient.

In some cases successfully applying this principle can be difficult. A general anesthetic for an operation can involuntarily cause damage, a serious complication even when it was needed and the intention was obviously good.

The principle of respect for autonomy is linked to self-determination. The ability and the right of the individual to decide what he thinks is best, to decide his destiny according to his conceptions and without influence, not having to obey or accept, necessarily, conceptions of others. The instinct for self-preservation makes every person, how rudimentary his basic knowledge may be, the sure judge of the conveniences of his own health. Likewise, the physician should choose the technique that will be applied while being able to accept the patient's choices; however, he will not be obliged to accept lay impositions that may incur useless risk or against the patient's integrity. This principle governs prior consent which must be presented in accessible language and may be revoked at any time at no charge. The physician may exercise persuasion, but never coercion, manipulation of information or unilateral imposition of conduct. In decision making anesthesiologists should include all patients, including minors, with language appropriate to their ability to understand the medical issues involved. ${ }^{4}$ Except in cases of emergency, the doctor-patient bond is sealed in the pre-anesthetic evaluation, with the informed consent signed by the patient or guardian. ${ }^{5}$

In some settings, patients have a widely recognized right to reject life-sustaining procedures, but this right has always been in conflict with the tradition of medical paternalism and authoritarianism derived from virtue-based ethics. ${ }^{6}$

The principle of justice leads to the obligation to provide healthcare to each patient according to what is morally correct, appropriate; and to give each one what is ethically due to him, the professional should act impartially, treating everyone equally, avoiding all social, cultural, religious, financial or other factors interfere with the patient's relationship. It can also be defined as a commitment to a fair distribution of finite resources, that is, balancing the needs of individual patients and economic management of limited clinical resources for the benefit of society. The provider should not distinguish or perform a procedure with different drugs, techniques, or monitoring patterns that differ according to a patient's social class or the way treatment is provided; good anesthesia must be the same for everyone.

In addition to the afore-mentioned four principles of bioethics, truthfulness, compassion, integrity, altruism, dignity, confidentiality, respect for an individual's rights and honesty are virtues of ethical behavior that physicians must also uphold.

The anesthetized patient is particularly vulnerable. Administering any type of anesthetic to him will be assuming full personal responsibility ("power of attorney") to protect him from any damage for as long as necessary until fully recovered. The inner world of the unconscious patient should be treated with the same respect, which we show when the patient is fully in possession of all senses. ${ }^{7}$ Anesthesiologists should monitor themselves and their colleagues to protect the anesthetized patient from any disrespectful or abusive behavior. ${ }^{5}$

Both in routine practice and in teaching activities, anesthesiologists have ethical responsibilities to their medical colleagues, so they should foster a cooperative and respectful relationship that facilitates quality medical care for patients. Operating room (OR) professionalism requires respect for the efforts and duties of other care providers, including physicians, medical students, nurses, technicians and assistants. The exercise of ethics becomes even more critical in teaching environments. Complex healthcare systems, where public and private health services are provided by the same staff, are sources of conflict of interest; in these situations it is important for young professionals to mirror good ethical models. ${ }^{8}$

Preventing potential conflicts and resolving the existing conflicts is necessary to optimize patient care and safety in the OR. Anesthesiologists have professional and scientific autonomy and not only provide the benefits of unconsciousness, sedation, analgesia and relaxation, but also resuscitate patients and provide life-sustaining measures to facilitate the surgeon's ability to care for the patient. The surgeon and the anesthesiologist should work as a team, working together during the perioperative period to achieve the best quality of care, the highest level of patient safety and the best outcome. This shared responsibility requires a clear definition of roles and mutual respect for competences. ${ }^{9}$

The OR is particularly prone to interpersonal conflicts as a wide range of healthcare professionals perform their tasks with overlapping and sometimes poorly defined areas of responsibility. In addition, the $\mathrm{OR}$ is an area of the hospital where two physicians of different specialties, each with their own professional autonomy, simultaneously share direct responsibility for the same patient. Moreover, the roles of these physicians are such that one cannot perform his task without the other. In such situations, a state of disagreement or disharmony between people or conduct may progress to a toxic work environment. ${ }^{10}$ 
The immediate postoperative outcome depends, among other factors, on how well members work together as a team and communicate. Positive synergy should be sought when there is a perception that working in groups surpasses the mark of individual production.

Performing surgical procedures in an accredited setting requires an environment in which all participants are treated with respect. Discrimination at any level, disruptive behavior, bullying and harassment behavior should be prohibited in daily activities and reported to ensure prompt corrective action is taken. ${ }^{9}$

Corrective actions, enforcement of OR policies and regulations require the cooperation of all those involved in patient care. Since OR conflicts can compromise surgical and anesthetic care, successful conflict resolution will promote better care and safety, better quality of care and better patient outcomes.

The main causes of conflict between a surgeon and the anesthesiologist include poor communication skills, competitiveness, different personality traits, different personal values and beliefs, lack of appreciation for the other specialty, and different models of financial compensation. Many factors turn out to be more stressful than the actual complications that can happen to the patient. In addition, treating sicker patients undergoing more complex surgical procedures may lead to potential conflicts involving futility, appropriate versus inappropriate indications for procedures, perioperative 'not-to-resuscitate' orders, early regulatory guidelines, institutional limitations, restrictions on the administration of blood products, among other causes. ${ }^{11}$

OR delays and cancellations are frequent sources of conflict. Some of the most common causes are the need for further examinations and consultations, poorly controlled systemic diseases, lack of essential equipment, availability of blood products, failure of preoperative fasting, and availability of postoperative beds for the critically ill patient. ${ }^{12}$ There should be agreements on risk stratification and optimization, and when there is disagreement, physicians should focus on individualized care, and on the risk-benefit ratio of the procedure in that particular patient. Many times this discussion may involve the patient or patient's guardian. Sometimes it is better to seek a second opinion from a colleague.

The anesthesiologist as a perioperative physician has a vital role to play in patient care during the postoperative period. Among many cares, acute pain relief is best provided by the anesthesiologist. In this age of outpatient surgery, anesthesiologists have much greater postoperative responsibilities until the patient's hospital discharge.

Ethical exercise can be compromised in some scenarios where medicine is highly judicialized, where fear of litigation leads doctors to engage in defensive medicine just to provide a good legal defence against any claims and to avoid accusations of negligence. The anesthesiologist may order additional tests, and often their costs may outweigh the benefits. Another contemporary consequence is over-prescription opioids.

Relationship with the pharmaceutical industry, artificial prolongation of life, confidentiality, excess of regulatory norms and conscientious objection are just some of the themes that allow the ethical reflection of the anesthesiologist's work.

Many discussions arise when thinking about how to allow a surgical or anesthetic innovation to be included in the routine. The risks, benefits, and alternatives of the procedure should be widely discussed to avoid patient harm. ${ }^{13}$ Financial interests, research, and other incentives, such as the demands by the pharmaceutical industry, influence medical decision making and compete with the primary obligation of patient care leading to conflicts of interest and ethical dilemmas. ${ }^{14}$

Anesthesiologists have ethical responsibilities to the health services in which they work and to this end need to direct efforts to review practice and help develop departmental or facility guidelines for the benefit of the health facility and all its patients. They should also observe and report to the appropriate authorities any potentially negligent practices or conditions that may pose a risk to patients or health facility personnel. When dealing with controlled and potentially hazardous substances, everyone, from the supplier to the end-user, has a responsibility to maintain an adequate monitoring system to prevent illicit use. $^{5}$

Ethics is a subject that permeates almost every area of life, and understanding the subject requires familiarity not only with the basic concepts of everyday life contextualized to the geographical region, social perspectives, demographics, and belief patterns, but also to workplace scenario. In this context the anesthesiologist has a distinct professional role. Acting with diplomacy, he needs to manage ethical problems with professionalism, and must be well related to the group, so that the ultimate goal, the well-being of the patient is satisfactorily achieved.

Financial support: None to declare

Conflicts of Interest: None to declare 


\section{REFERENCES}

1. Udelsmann A. Bioethics - Issues regarding the anesthesiologist. Rev Bras Anestesiol 2006;56:3:325-33. [PubMed]

2. Beauchamp TL, Childress JF. Principles of biomedical ethics. 4th ed. New York: Oxford University Press; 1994.

3. Grant SB, Modi PK, Singer EA. Futility and the Care of the Perioperative. In: Jericho BG. Ethical Issues in Anesthesiology and Surgery. Springer International Publishing, Switzerland. 2015:151-70.

4. Feinstein MM, Pannunzio AE, Lobell S, Kodish E. Informed Consent in Pediatric Anesthesia: A Narrative Review. Anesth Analg. 2018;127(6):1398405. [PubMed] DOI: 10.1213/ ANE. 0000000000003705

5. Guidelines for the Ethical Practice of Anesthesiology. https://www. asahq.org/standards-and-guidelines/ guidelines-for-the-ethical-practiceof-anesthesiology. Developed By: Committee on Ethics. Last Amended: October 17, 2018 (original approval:
October 15, 2003). Accessed in: December 13, 2019.

6. Van Norman GA, Rosenbaum S. Ethical aspects of anesthesia care. In: Miller RD, ed. Miller's Anesthesia. Vol 1. 7th ed. Philadelphia, PA: Elsevier Churchill Livingstone; 2010:209-220.

7. Cheek DB. Unconscious perception of meaningful sounds during surgical anesthesia as revealed under hypnosis. Am J Clin Hypn 1959;1:101-13. DOl: $\frac{10.1080 / 00029157.1959 .10401774}{\text { S. }}$

8. Hariharan S. Ethical issues in anesthesia: the need for a more practical and contextual approach in teaching. J Anesth 2009;23:409-12. [PubMed] DOl: $10.1007 / \mathrm{s} 00540-009-$ $\underline{0776-x}$

9. Ferreres AR. Professionalism in the operating room. In: Jericho BG. Ethical Issues in Anesthesiology and Surgery. Springer International Publishing, Switzerland 2015:127-37.

10. Katz JD. Conflict and its resolution in the operating room. J Clin Anesth. 2007;19:152-8. [PubMed]

11. Cahana $A$, Weibel $H$, Hurst $S A$.
Ethical decision-making: do anesthesiologists, surgeons, nurse anesthetists and surgical nurses reason similarly? Pain Med. 2008;9:728-36. [PubMed]

12. van Klei WA, Moons KG, Rutten $\mathrm{CL}$, Schuurhuis A, Knape JT, Kalkman $\mathrm{CJ}$, et al. The effect of outpatient preoperative evaluation of hospital inpatients on cancellation of surgery and length of hospital stay. Anesth Analg 2002;94:644-9. [PubMed] DOl: 10.1016/i.jclinane.2006.07.007

13. Ray S, O'Connor M, Angelos P. Ethical challenges in high-risk innovative surgery. In: Jericho BG. Ethical Issues in Anesthesiology and Surgery. Springer International Publishing, Switzerland. 2015:117-26.

14. Attri JP, Sandhu GK, Mohan B, Bala N, Sandhu KS, Bansal L. Conflicts in operating room: Focus on causes and resolution. Saudi J Anaesth. 2015;9:457-63. [PubMed] [Free Full Text] doi: 10.4103/1658354X.159476.

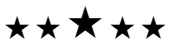

